\title{
Principles of Nerve Repair in Complex Wounds of the Upper Extremity
}

\author{
Amy M. Moore, $\mathrm{MD}^{1} \quad$ I. Janelle Wagner, $\mathrm{MD}^{1} \quad$ Ida K. Fox, $\mathrm{MD}^{1}$ \\ ${ }^{1}$ Division of Plastic and Reconstructive Surgery, Department of \\ Address for correspondence Ida K. Fox, MD, Suite 1150, Northwest \\ Surgery, Washington University School of Medicine, \\ St. Louis, Missouri \\ Tower, 660 South Euclid Avenue, Campus Box 8238, St. Louis, MO \\ 63110 (e-mail: foxi@wudosis.wustl.edu).
}

Semin Plast Surg 2015;29:40-47.
Abstract
Keywords
- upper extremity trauma
- peripheral nerve injury
- nerve transfer
- processed nerve allograft
- nerve conduit
- mutilating injury of the hand
Peripheral nerve injuries are common in the setting of complex upper extremity trauma. Early identification of nerve injuries and intervention is critical for maximizing return of function. In this review, the principles of nerve injury, patient evaluation, and surgical management are discussed. An evidence-based approach to nerve reconstruction is reviewed, including the benefits and limitations of direct repair and nerve gap reconstruction with the use of autografts, processed nerve allografts, and conduits. Further, the principles and indications of commonly used nerve transfers in proximal nerve injuries are also addressed.

Peripheral nerve injuries are common in the setting of complex upper extremity trauma. When evaluating patients with significant limb trauma, it is critical to identify and manage the concomitant nerve injuries. Without restoration of motor and sensory function, the salvaged limb becomes an insensate, and often painful, inanimate prosthetic.

Previous reports have described straight-forward brachial plexus and nerve injury management strategies. ${ }^{1,2}$ In the following, our goal is to present a pragmatic approach to restore peripheral nerve function in the setting of highimpact upper extremity trauma. The principles of nerve injury, patient evaluation, and surgical management are discussed.

\section{Principles of Nerve Injury}

\section{Mechanism of Injury}

Injury mechanism determines the appropriate evaluation and management strategy. An open and sharp transection nerve injury demands a very different approach from a closed crush or gunshot wound injury pattern. Defining the nerve injury will also predict potential recovery of function.
The classification of nerve injury was first described by Seddon and later revised by Sunderland and Mackinnon. The degree of nerve injury can range from a temporary neurapraxia with spontaneous full recovery to a transection that requires surgery to achieve any recovery (-Table $\mathbf{1}) .^{2,3}$ In general, types I-III and VI (neuroma-in-continuity) nerve injury patterns are generally associated with closed or gunshot wound mechanisms of injury (i.e., crush, stretch, and avulsion) and demand a more measured approach (including watchful waiting with serial examinations). Gunshot wounds are often treated as "closed injuries" because although an open wound exists, the blast mechanism often causes a neurapraxia or mixed injury pattern rather than an actual nerve transection. ${ }^{4,5}$ In contrast, any open wound (laceration or penetration of the skin and soft tissue) with an associated sensory or motor nerve deficit is assumed to be a type $V$ injury until proven otherwise by direct inspection during surgical exploration.

\section{Timing of Surgical Intervention}

Understanding timing is critical to successfully treating peripheral nerve injuries. There are advantages and disadvantages to
Issue Theme Complex Upper Extremity Reconstruction; Guest Editors, Morad Askari, MD, and Steven L. Moran, MD
Copyright $\odot 2015$ by Thieme Medical Publishers, Inc., 333 Seventh Avenue, New York, NY 10001, USA. Tel: +1(212) 584-4662.
DOI http://dx.doi.org/ 10.1055/s-0035-1544169. ISSN 1535-2188. 
Table 1 Degree of nerve injury and anticipated recovery

\begin{tabular}{|c|c|c|c|c|}
\hline $\begin{array}{l}\text { Degree of nerve } \\
\text { injury }\end{array}$ & Definition of nerve injury & Prognosis & Tinel sign & $\begin{array}{l}\text { Surgical } \\
\text { intervention }\end{array}$ \\
\hline First (Neurapraxia) & $\begin{array}{l}\text { Segmental demyelination } \\
\text { Axonal continuity } \\
\text { maintained; } \\
\text { endoneurium, perineurium } \\
\text { and epineurium, intact }\end{array}$ & Favorable & None & $\begin{array}{l}\text { None, distal } \\
\text { decompression }\end{array}$ \\
\hline $\begin{array}{l}\text { Second } \\
\text { (Axonotmesis) }\end{array}$ & $\begin{array}{l}\text { Discontinuity of axon and } \\
\text { myelin; } \\
\text { endoneurium, perineurium, } \\
\text { and epineurium intact }\end{array}$ & Favorable & $\begin{array}{l}\text { Present, } \\
\text { progressive }\end{array}$ & $\begin{array}{l}\text { None, distal } \\
\text { decompression, } \\
\text { supercharge } \\
\text { procedure }\end{array}$ \\
\hline Third & $\begin{array}{l}\text { Discontinuity of axon, myelin } \\
\text { and endoneurium; } \\
\text { perineurium and epineurium } \\
\text { intact }\end{array}$ & Favorable & $\begin{array}{l}\text { Present, } \\
\text { progressive }\end{array}$ & $\begin{array}{l}\text { None, distal } \\
\text { decompression, } \\
\text { supercharge } \\
\text { procedure }\end{array}$ \\
\hline Fourth & $\begin{array}{l}\text { Only the epineurium remains } \\
\text { intact }\end{array}$ & Unfavorable & $\begin{array}{l}\text { Present; no } \\
\text { progression }\end{array}$ & $\begin{array}{l}\text { Nerve repair, graft, } \\
\text { transfer }\end{array}$ \\
\hline Fifth (Neurotmesis) & Complete nerve transection & Unfavorable & $\begin{array}{l}\text { Present; no } \\
\text { progression }\end{array}$ & $\begin{array}{l}\text { Nerve repair, graft, } \\
\text { transfer }\end{array}$ \\
\hline Sixth & Mixed injury pattern & Variable & Variable & $\begin{array}{l}\text { All options may be } \\
\text { appropriate }\end{array}$ \\
\hline
\end{tabular}

acute versus subacute surgery. Nerve growth is estimated to occur at a 1 to $3 \mathrm{~mm} / \mathrm{d}^{6}$ Further, there is a critical window of time to maintain viability of the motor end plates. ${ }^{7,8}$ Although the precise window is unknown, reinnervation of the target muscle by 12 to 18 months is preferable to maximize return of function. We refer to the mantra "time is muscle" and consider the estimated time of nerve regeneration when planning our reconstruction. Although repairs performed acutely provide the timeliest restoration of motor function, there are also advantages to delayed repair.

The advantages of acute repair include the ability for intraoperative stimulation, avoidance of potentially challenging scar tissue, and the optimization of motor recovery. Within 72 hours of injury, the distal nerve ends contain neurotransmitters and intraoperative motor stimulation allows enhanced topographical alignment. Intervention prior to edema and scar tissue formation also makes exploration and acute repair easier from a technical standpoint.

On the other hand, determining the extent of nerve injury acutely is challenging in superimposed avulsion, blast, stretch, and/or crush mechanisms of injury. Although the open injury suggests nerve transection, these more complex patterns of open injury may be better treated subacutely to establish the zone of nerve injury. During the initial exploration and debridement, the nerve ends may be tagged for later repair. Specifically, we use 3/0 and $4 / 0$ Prolene suture to secure the nerve endings in the appropriate matching orientation to the underlying muscle bed after careful identification and stimulation of the distal ends. Definitive reconstruction is then performed in 2 to 3 weeks. In many cases, this delay also allows for adequate debridement of the extremity, treatment of associated injuries and/or infection, and coordination of definitive soft tissue coverage.
One unique scenario best managed with immediate nerve repair is in the setting of vessel injury and repair. These potentially life- and limb-threatening injuries require emergent exploration and limit the preoperative exam. Maintaining a high index of suspicion allows for identification of the associated nerve injury. At our institution, we are often consulted by the vascular surgery service for concomitant major peripheral nerve injuries associated with brachial artery transection at the upper arm and antecubital fossa (-Fig. 1). If the patient is stable, we perform immediate nerve repair (often with interposition grafts) and fasciotomies once perfusion has been re-established. Although delayed distal nerve transfers or extraanatomic grafts are possible, reconstruction at the time of vascular repair, particularly in the setting of multiple nerve transections, affords the greatest opportunity for recovery of function and avoidance of secondary disruption of the arterial repair.

In contrast to open injury patterns, the treatment of closed or gunshot wound injuries with nerve deficits involves deliberately delayed surgical intervention after serial evaluation. Serial exam and testing allow for evaluation of spontaneous recovery, which may not require surgery. However, the complete absence of reinnervation or recovery by 12 to 16 weeks after a closed injury warrants operative intervention as discussed below.

\section{Evaluation}

\section{History}

When evaluating patients, factors such as age, overall health, baseline level of function, and occupation should be considered. This may be limited by associated life-threatening issues that preclude comprehensive history-taking. Close communication between providers (prehospital, emergency 


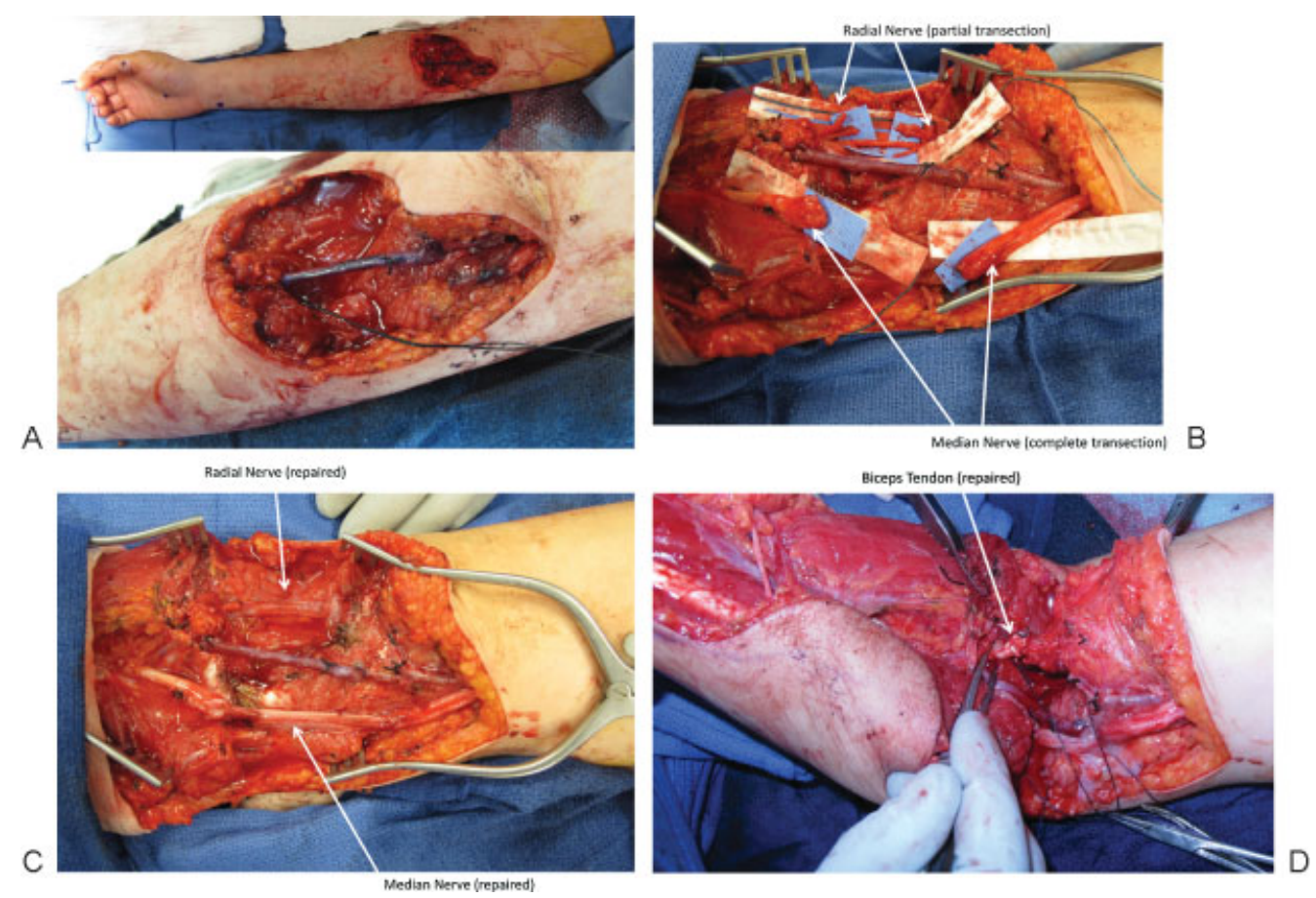

Fig. 1 Intraoperative images of reconstruction of the median and partial radial nerves with nerve grafting in the setting of a brachial artery repair. (A) Right arm wound after vein grafting of the brachial artery. (B) Median and radial nerves identified. (C) Median and radial nerve repaired with autograft cables. (D) Repair of the biceps tendon to complete the reconstruction of the extremity after a complex laceration.

department, trauma and vascular surgery, anesthesiology, and others) can help in elucidating the following information. First, is the patient stable enough for a complex (long duration) nerve reconstruction procedure? Second, does the initial injury pattern suggest the need for serial debridement (crush, blast, avulsion, and contaminating mechanisms) that would advise against acute repair? Finally, are there more upstream injuries (closed head, spinal cord, or brachial plexus) that will affect or complicate the peripheral nerve repair results? Of note, the latter does not necessarily preclude repair-which is time sensitive and critical to overall restoration of function-but might influence choices and approaches.

For more subacute presentation, obtain information about the mechanism, level, and timing of injury. Review the initial functional deficit and any changes over time with and without previous surgical intervention. Address information about pain, edema, and stiffness. Recalcitrant nerve pain and/or complex regional pain syndrome may preclude future functional use if not treated. However, sometimes, the nerve repair (by giving transected sensory nerve fibers an appropriate target end organ) can in and of itself be partially therapeutic.

\section{Pertinent Physical Examination}

Although a thorough upper extremity and hand examination should be completed, other components of the exam are important in this patient population. A general examination that determines patient cognitive ability, functional status, pain and effort levels, and mental status are often helpful. Examination of donor sites for nerve graft or nerve transfer, functional muscle transfer, or flap coverage is also important. Characteristics of the wound including degree of contamination, viability of the affected tissue and limb (a handheld Doppler can be useful in determining the course of previous vascular interposition graft or direct repairs), mobility and other qualities of the soft tissue envelope are important when determining the feasibility of surgical interventions.

A complete neurologic exam incorporates both a motor and sensory evaluation. We also recommend the use of a pain diagram wherein the patient draws areas of impaired sensation and discomfort. ${ }^{9}$ A standard motor exam using the Medical Research Council (MRC) grading scale is completed. Sensory testing is completed using two-point discrimination and Semmes-Weinstein monofilaments. Importantly, clinical evidence of spontaneous regeneration by an advancing Tinel sign along the course of the injured nerve and/or gain in function from proximal to distal is promising.

\section{Diagnostic Testing}

Radiologic and electrodiagnostic testing must be tailored to individual patterns of injury to further delineate the extent of nerve injury, the availability of donor nerves for nerve transfer, and the presence or absence of superimposed pathology such as concomitant neuropathy, brachial plexus, or more proximal injuries.

\section{Imaging}

Plain X-rays ensure baseline bony stability and assess for other injuries. For example, a scapular or clavicular fracture implies a superimposed proximal suprascapular nerve and/or brachial plexus injury respectively. A chest X-ray showing 
associated rib fractures or phrenic nerve injury may preclude the use of intercostal nerves as donors. Abnormal magnetic resonance imaging (MRI) or computed tomography (CT) myelograms of the cervical spinal cord and roots that suggest superimposed or isolated root level avulsion injury will dramatically change management options and strategies.

\section{Electrodiagnostic Studies}

Electrodiagnostic studies complement a serial physical examination, particularly in complex closed and gunshot wound injuries. They provide information about the following: degree of nerve injury (complete or incomplete), pattern of injury (heterogenous or isolated), and provide information about spontaneous subclinical recovery and nerve transfer donor function. ${ }^{10,11}$ Although earlier testing can be performed, we prefer to obtain the first electrodiagnostic tests at 10 weeks from injury when muscle reinnervation can be detected.

A nerve conduction study (NCS) provides quantitative data about the degree of axon loss and assists in determining a superimposed complete or incomplete brachial plexus injury, nerve compression, or other process such as diabetic neuropathy. The NCS can be used to confirm a simple conduction block (type 1-neurapraxia) injury. However, in peripheral nerve trauma, electromyography (EMG) of the specific muscle groups of interest is often the most clinically relevant diagnostic tool.

Electromyography of both the injured and uninjured (possible donor for nerve transfer procedure) muscles can provide valuable information. To properly interpret these results, it is important to understand the components of the EMG. First, fibrillations imply axonal injury and confirm the clinically suspected injury. The presence of fibrillations in putative clinically normal donors (for nerve or muscle transfer) indicates damage and may change treatment strategies. In the injured muscles, nascent units and motor unit potentials (MUPS) may be seen prior to clinically detectable movement. This is encouraging and suggests that partial or complete recovery may occur. ${ }^{10,11}$ Motor unit potentials occur at 8 to
12 weeks and are the result of collateral sprouting from any residual fibers that are in contact with the motor end plates. ${ }^{10,11}$ Nascent units occur with regeneration of native injured axons to the motor end plate and may take longer to appear depending on the length of regeneration required. ${ }^{10,11}$

It should be noted that close communication with the electrodiagnostician and a clear understanding of the limitations of the test (some patients are unable to tolerate multiple studies, neighboring muscles can be challenging to differentially assess, patient size may limit ability for needle to reach muscle) is critical-clinical evidence of improved function should always take precedence over results of tests.

\section{Surgical Management}

Surgical intervention will depend upon the mechanism and pattern of nerve injury as well as the overall viability of the extremity and the health of the patient (-Fig. 2). Surgical options include direct primary repair, repair with an interposition nerve graft or other material, distal nerve transfer or other adjunctive procedures such as tendon transfers, arthrodesis or free functional muscle transfers. In the following section, we will discuss a few of the most common treatment strategies to show the gamut of possibilities for nerve reconstruction in the traumatized limb.

\section{Primary Repair}

Direct end-to-end repair is often not an option in complex trauma due to segmental damage. In addition, in very proximal nerve injury, primary repair may be less attractive due to the inability to reach distal muscle, such as the hand intrinsic muscles, in a timely fashion. However, a tensionless primary repair can be considered in cases of distal (near or below the elbow), isolated, single nerve injuries. This should also be considered in more proximal injury patterns that involve multiple nerves where options are limited as there are few redundant donors available for more distal nerve or tendon

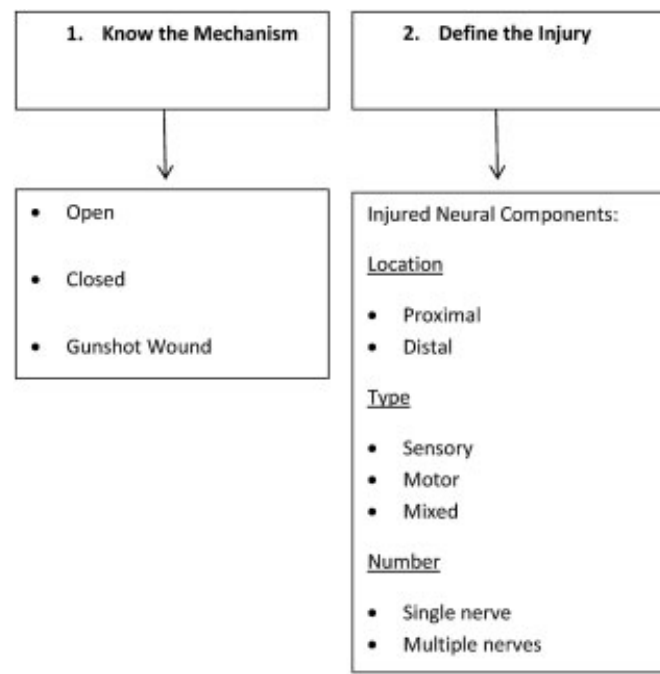

Fig. 2 Key principles of nerve management in complex trauma.

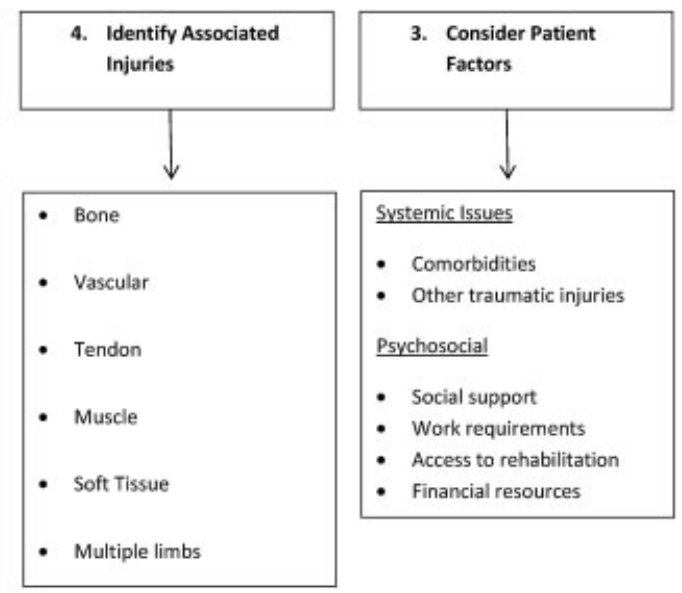


transfer surgeries. Direct repair is also a reasonable first choice for any level isolated sensory nerve repair to improve/treat neuropathic pain and because the restoration of sensation is not time sensitive.

Paying attention to the technical details of a nerve repair will result in improved outcomes. Getting outside the zone of injury is difficult to determine, but critical for success. Under $4 \times$ magnification or higher, the nerve should be trimmed ("bread loafed") proximally and distally back to bulging fascicles. An option to confirm adequate resection is to trim the proximal cut end while the anesthetic is decreasedchange in heart rate or blood pressure suggests a nociceptive response. Importantly, a direct repair should be done in a tension-free fashion with fascicular matching of the proximal and distal ends to optimize return of critical function. Using abnormal postures or joint flexion positions to coapt cut nerve ends is unacceptable. Generally an $8 / 0$ - or $9 / 0$-size nylon suture should be used with microscopic magnification. If two 8/0 nylon epineurial stiches separated at 180 degrees cannot hold the cut nerve ends together easily, an interposition nerve graft should be performed.

\section{Treatment of Segmental Nerve Defects}

\section{Autografts}

Traditionally, repairs of large, segmental, or complex nerve injuries have been performed using autologous nerve grafts, i.e., autografts. Autografts provide the necessary components for nerve regeneration including viable Schwann cells, endoneurial tubes, and extracellular matrix. ${ }^{12}$ Donor autografts are typically chosen based on their caliber, the length of the nerve gap, donor site morbidity, ease of harvest, and occasionally recipient nerve modality (i.e., sensory or motor). Although animal studies have demonstrated that injured motor and sensory nerves preferentially grow into matched grafts with similar motor/sensory specificity, this is not commonly performed clinically. ${ }^{13,14}$ Due to the ease of harvest, the long length, and minimal donor site morbidity, one of the most commonly used autograft donors is the sural nerve; the medial antebrachial cutaneous (MABC) is also easily harvested and often avoids a second surgical site. In general, we use autologous graft (including sural, saphenous, $M A B C$, lateral antebrachial cutaneous, obturator branch to the gracilis, and spare parts' nerves) to restore critical motor function and critical areas of sensation (contact surfaces).

Although there are numerous strengths of the use of autografts, they do have limitations. For one, there is a finite supply of expendable nerve graft and this becomes greatly apparent in ballistic/combat trauma when multiple extremities are involved. Further, nerve autografts are associated with increased operative time and donor site morbidity including sensory loss, scarring, and debilitating neuroma formation. $^{15}$

\section{Synthetic Conduits and Processed Nerve Allografts}

Nerve substitutes include synthetic conduits and processed nerve allografts (PNAs). Seven synthetic nerve conduits, four synthetic nerve wraps, and one PNA are currently approved for use by the US Food and Drug Administration (FDA). ${ }^{16}$ Conduits and PNAs are appealing because they (1) provide a means for supporting regeneration across the nerve gap; (2) remove tension from the repair; (3) prevent scar tissue infiltration; (4) are readily available in a variety of lengths and diameters, and (5) can be taken "off the shelf" as needed. ${ }^{15,17}$ Further, PNAs contain endoneurial microstructure. ${ }^{18}$ However, both PNAs and conduits currently lack viable SCs, which is a significant reason for their limited clinical utility and effectiveness ( - Table 2 ). ${ }^{18,19}$

Synthetic conduits have demonstrated success in small diameter sensory nerves such as the digital nerves in the hand; however, failure of regeneration has been reported with larger diameter nerves and greater gap lengths. ${ }^{19}$ The limitations of conduits is attributed to the volume of the conduit and dilution of the concentration of neurotrophic factors, leading to less tropic and trophic support of nerve regeneration. ${ }^{19}$ Further studies are needed to determine the exact parameters and critical volumes for successful regeneration. Until then caution is needed when using conduits to repair large diameter nerve defects with long gap lengths. In our practice, the indication for conduit use is limited to

Table 2 Benefits, limitations, and indications of nerve gap fillers

\begin{tabular}{|c|c|c|c|}
\hline Material & Pros & Cons & Indication \\
\hline Conduit & $\begin{array}{l}\text { Available "off the shelf" } \\
\text { Inexpensive }\end{array}$ & $\begin{array}{l}\text { Lacks Schwann cells } \\
\text { Lacks nerve architecture } \\
\text { Lacks vasculature }\end{array}$ & $\begin{array}{l}\text { Gap }<3 \mathrm{~cm} \\
\text { Sensory nerves } \\
\text { Diameter }<3 \mathrm{~mm}\end{array}$ \\
\hline $\begin{array}{l}\text { Processed nerve allograft } \\
\text { (i.e., Avance, Axogen Nerve Graft) }\end{array}$ & $\begin{array}{l}\text { Available "off the shelf" } \\
\text { Retained nerve architec- } \\
\text { ture (endoneurial tubes } \\
\text { and extracellular matrix) }\end{array}$ & $\begin{array}{l}\text { Expensive } \\
\text { Lacks Schwann cells } \\
\text { Lacks vasculature }\end{array}$ & $\begin{array}{l}\text { Gap } \leq 3 \mathrm{~cm} \\
\text { Sensory nerves } \\
\text { Alternative for motor or } \\
\text { mixed nerve recon- } \\
\text { struction when auto- } \\
\text { graft not available }\end{array}$ \\
\hline Autograft & $\begin{array}{l}\text { Gold standard } \\
\text { Nerve architecture } \\
\text { Schwann cells } \\
\text { Nerve vasculature }\end{array}$ & $\begin{array}{l}\text { Donor site deficit } \\
\text { Donor site scar } \\
\text { Limited expendable } \\
\text { supply (especially in } \\
\text { multiple nerve or limb } \\
\text { trauma) }\end{array}$ & $\begin{array}{l}\text { All nerve gaps lengths } \\
\text { (Ideally }<6 \mathrm{~cm} \text { ) } \\
\text { Sensory, motor, mixed } \\
\text { nerve injuries }\end{array}$ \\
\hline
\end{tabular}


isolated noncritical digital nerve injury at the level of the hand and finger(s).

Processed nerve allografts (PNAs) have had variable levels of success in research and clinical realms. They preserve the three-dimensional scaffolding and endoneurial architecture present within native nerve tissue, which promote cell migration and nerve fiber elongation. ${ }^{20}$ Currently, one FDAapproved, PNA is commercially available, the Avance nerve graft by AxoGen, Inc (Alachua, FL). This PNA is made of cadaveric human tissue that is rendered nonimmunologic and is then prepared using a proprietary protocol. ${ }^{21,22}$ Animal research studies, show improved regeneration through PNAs (over conduits), but have failed to demonstrate regeneration equivalent to autografts. ${ }^{18,23}$ Clinically, there are few published reports and case series demonstrating the efficacy and safety of the use of Avance grafts. ${ }^{24-26}$

Further comparative human trials are needed to delineate the appropriate indications and limitations for the use of PNAs particularly in cases when autograft material is available. Given the current data, we recommend PNAs for use in small diameter nerves injuries with $<3 \mathrm{~cm}$ nerve gap defects. We most often use these for repair of isolated noncritical areas of sensation or to extend the length of transected and painful sensory nerves to bury in uninjured tissue in the treatment of posttraumatic neuroma.

\section{Nerve Transfers}

Despite technically perfect repairs, functional outcomes are often disappointing in the primary repair of proximal motor nerve injury. As our knowledge of nerve anatomy and topography has grown, distal nerve transfers have become an important and successful surgical tool to restore improved function in a more timely fashion.

A nerve transfer coapts a healthy expendable donor to a denervated recipient to restore sensory or motor function. Nerve transfers have numerous advantages. First, they can be performed closer to the end-organ target. This results in earlier reinnervation and faster return of function. Nerve transfers also avoid operating in the scarred field of the nerve injury and ensure that the coaptation is performed outside of the zone of injury. They also avoid the use of interpositional nerve grafts and the potential loss of healthy axons at multiple coaptations. Lastly, nerve transfers require minimal postoperative immobilization and can be used in the setting of significant stiffness. However, patients require postoperative motor re-education to maximize return of function. ${ }^{2}$

In complex upper extremity trauma, utilization of nerve transfers is ideal. In the following we will discuss the most common nerve transfers to restore function in the proximal injuries of the radial, median, ulnar, and combined nerve injury patterns.

\section{Radial Nerve Injury}

The radial nerve is frequently injured with upper extremity trauma. Proximal radial nerve injuries result in lack of wrist and finger extension with diminished grip strength and hand function. ${ }^{27}$ Nerve transfers to restore radial nerve function are particularly useful for patients with hand stiffness and/or complex regional pain syndrome who may otherwise not be ideal candidates for tendon transfers. To restore radial nerve function, distal nerve branches from the median nerve are transferred to the radial nerve branches. Specifically, the flexor digitorum superficialis nerve is coapted to the extensor carpi radialis brevis (ECRB) to restore wrist extension. The flexor carpi radialis nerve is transferred to the posterior interosseous nerve (PIN) to restore finger and thumb extension. ${ }^{28-30}$ These transfers capitalize on synergistic motion of the wrist and hand, and thus simplify postoperative re-education. Further, the nerve transfers allow independent thumb and finger extension due to the reinnervation of each individual muscle innervated via the PIN. ${ }^{28,31,32}$ However, it does take about a year for complete return of function with nerve transfers and the patient must decide whether nerve or traditional tendon transfers is a better fit for them.

\section{Median Nerve Injury}

Nerve transfers for reconstruction of median nerve injuries are dependent on the location and severity of the nerve injury. In a high median nerve injury, forearm pronation, wrist, finger and thumb flexion, thumb opposition, and sensation are lost. Nerve transfers to restore median nerve function have been described using the branches of the radial nerve, the brachialis branch of the musculocutaneous nerve, and branches of the ulnar nerve. ${ }^{29,31,33}$

Pronation is a critical function provided by the median nerve and is necessary to perform many of the independent activities of daily living. ${ }^{34,35}$ Multiple nerve transfers to restore pronation have been described, but using nerve branch to the ECRB to the pronator teres branch is reliable and capitalizes synergistic movement patterns of wrist extension and pronation. ${ }^{34}$ Nerve transfers can also be used to restore finger and thumb flexion innervated by the median nerve. Branches from the musculocutaneous, radial or ulnar nerves have been used to reinnervate the anterior interosseous nerve (AIN). ${ }^{34,36-38}$ In high median nerve injuries, the brachialis branch of the musculocutaneous nerve can be transferred directly to the AIN with successful return of thumb and finger flexion. ${ }^{37}$ This transfer is only performed in patients with an intact musculocutaneous nerve and normal elbow flexion to avoid downgrading upper extremity function.

Thumb opposition is the final critical motor function provided by the median nerve. In isolated low median nerve injuries that are not amenable to direct repair or short interpositional grafting, restoration of thumb opposition has been provided by nerve transfers from proximal branches of the median, specifically the terminal AIN supplying the pronator quadratus muscle. An interposition graft is usually needed for this transfer, but clinical studies have shown this transfer to be viable and effective. ${ }^{39-41}$ Traditional opponensplasty tendon transfers (using extensor indicis proprius or extensor digiti minimi) are also reasonable.

\section{Ulnar Nerve Injury}

Ulnar nerve injuries result in significant loss of power grip, pinch strength, and hand dexterity. ${ }^{42,43}$ In proximal ulnar 
nerve injury, primary or interposition graft repair may result in reasonable return of extrinsic motor and sensory function. However, due to the time required to successfully regenerate to the hand, most adults will not regain meaningful intrinsic ulnar motor function. Therefore, more distal nerve transfers for timely restoration of this critical component should be completed.

In isolated proximal ulnar nerve injury, the terminal median nerve/anterior interosseous nerve branch to pronator quadratus (PQ) donor is transferred to the motor branch of the ulnar nerve. This transfer may be performed in an end-toend ${ }^{39,44-46}$ or "supercharge" (reverse end-to-side) fashion. ${ }^{47}$ In the supercharge transfer, the PQ is cut distally and coapted to the side of the deep motor branch. This allows for native ulnar nerve recovery to continue unimpeded (particularly in closed, mixed nerve injury patterns) while augmenting or "rescuing" motor intrinsic function in a more timely fashion by use of the distal transfer. ${ }^{47-49}$

In combined proximal ulnar and median nerve injury, ulnar intrinsic function can be restored using nerve transfer of radial nerve branches such as extensor digiti minimi and extensor carpi ulnaris donors with an interposition graft ${ }^{50}$ or directly using abductor pollicis longus, extensor pollicis brevis, and extensor indicis proprius via a transinterosseous membrane tunnel. ${ }^{51}$ In these combined injury patterns, as previously discussed, primary or interposition grafting to repair the proximal injury site should also be completed to restore some extrinsic wrist and finger flexion.

\section{Adjunctive Operative Techniques}

These strategies include a supercharge end-to-side nerve transfer to provide protection of the muscle while allowing proximal regeneration of the native nerve, distal nerve decompressions to enhance regeneration after proximal nerve repair, and combining both nerve and early "babysitter" tendon transfers to provide function while awaiting muscle reinnervation. In more complex injury patterns, free functional muscle transfers are also a viable option to provide function to an injured extremity. If donor nerves are acutely limited to provide innervation to the free muscle, then a staged reconstruction can be employed. The first stage involves coapting a long nerve graft to a viable donor (e.g., intercostals and/or nerves to the rectus muscle). We refer to this first stage as "banking" the nerve graft. The second stage occurs one year later when a free functional muscle is transferred and coapted to this banked nerve graft to restore function.

More extensive discussion of additional techniques including tendon transfer, tenodesis, fusion, and others are outside the scope of this article, but must also be considered.

\section{Conclusion}

Complex peripheral nerve injuries of the upper extremity are challenging to manage. They require an understanding of not only the mechanism and type of nerve injury, but also the timing of repair. Closed injuries benefit from serial examinations to determine extent of injury and recovery, whereas open or sharp injuries benefit from expeditious operative exploration and repair. These characteristics guide surgical decision making.

Options for repair are numerous and include primary repair, grafting, nerve and tendon transfer, and free functional muscle transfer. Careful history and physical examination, along with the judicious use of electrodiagnostic and radiologic studies are just the beginning of the complex management algorithms of peripheral nerve injuries, and are tempered with an experienced approach to repair. One has to be careful not to downgrade function by intervening too early in a closed injury. Yet care should be taken not to intervene too late, precluding motor recovery, in an open nerve injury. All the tools in one's armamentarium should be considered, while individualized care in response to the unique attributes of these complex cases is applied.

\section{References}

1 Fox IK, Mackinnon SE. Adult peripheral nerve disorders: nerve entrapment, repair, transfer, and brachial plexus disorders. Plast Reconstr Surg 2011;127(5):105e-118e

2 Moore AM, Novak CB. Advances in nerve transfer surgery. J Hand Ther 2014;27(2):96-104, quiz 105

3 Mackinnon SE. New directions in peripheral nerve surgery. Ann Plast Surg 1989;22(3):257-273

4 Secer HI, Daneyemez M, Tehli O, Gonul E, Izci Y. The clinical, electrophysiologic, and surgical characteristics of peripheral nerve injuries caused by gunshot wounds in adults: a 40-year experience. Surg Neurol 2008;69(2):143-152, discussion 152

5 Bercik MJ, Kingsbery J, Ilyas AM. Peripheral nerve injuries following gunshot fracture of the humerus. Orthopedics 2012;35(3): e349-e352

6 Seddon HJ, Medawar PB, Smith H. Rate of regeneration of peripheral nerves in man. J Physiol 1943;102(2):191-215

7 Kobayashi J, Mackinnon SE, Watanabe O, et al. The effect of duration of muscle denervation on functional recovery in the rat model. Muscle Nerve 1997;20(7):858-866

8 Fu SY, Gordon T. Contributing factors to poor functional recovery after delayed nerve repair: prolonged denervation. J Neurosci 1995;15(5 Pt 2):3886-3895

9 Bailey R, Kaskutas V, Fox I, Baum CM, Mackinnon SE. Effect of upper extremity nerve damage on activity participation, pain, depression, and quality of life. J Hand Surg Am 2009;34(9):1682-1688

10 Campbell WW. Evaluation and management of peripheral nerve injury. Clin Neurophysiol 2008;119(9):1951-1965

11 Willmott AD, White C, Dukelow SP. Fibrillation potential onset in peripheral nerve injury. Muscle Nerve 2012;46(3):332-340

12 Millesi H. Bridging defects: autologous nerve grafts. Acta Neurochir Suppl (Wien) 2007;100:37-38

13 Brenner MJ, Hess JR, Myckatyn TM, Hayashi A, Hunter DA, Mackinnon SE. Repair of motor nerve gaps with sensory nerve inhibits regeneration in rats. Laryngoscope 2006;116(9):1685-1692

14 Nichols CM, Brenner MJ, Fox IK, et al. Effects of motor versus sensory nerve grafts on peripheral nerve regeneration. Exp Neurol 2004;190(2):347-355

15 Ray WZ, Mackinnon SE. Management of nerve gaps: autografts, allografts, nerve transfers, and end-to-side neurorrhaphy. Exp Neurol 2010;223(1):77-85

16 Kehoe S, Zhang XF, Boyd D. FDA approved guidance conduits and wraps for peripheral nerve injury: a review of materials and efficacy. Injury 2012;43(5):553-572

17 Taras JS, Nanavati V, Steelman P. Nerve conduits. J Hand Ther 2005; 18(2):191-197 
18 Moore AM, MacEwan M, Santosa KB, et al. Acellular nerve allografts in peripheral nerve regeneration: a comparative study. Muscle Nerve 2011;44(2):221-234

19 Moore AM, Kasukurthi R, Magill CK, Farhadi HF, Borschel GH, Mackinnon SE. Limitations of conduits in peripheral nerve repairs. Hand (NY) 2009;4(2):180-186

20 Hudson TW, Zawko S, Deister C, et al. Optimized acellular nerve graft is immunologically tolerated and supports regeneration. Tissue Eng 2004;10(11-12):1641-1651

21 Krekoski CA, Neubauer D, Zuo J, Muir D. Axonal regeneration into acellular nerve grafts is enhanced by degradation of chondroitin sulfate proteoglycan. J Neurosci 2001;21(16):6206-6213

22 Neubauer D, Graham JB, Muir D. Chondroitinase treatment increases the effective length of acellular nerve grafts. Exp Neurol 2007;207(1):163-170

23 Whitlock EL, Tuffaha SH, Luciano JP, et al. Processed allografts and type I collagen conduits for repair of peripheral nerve gaps. Muscle Nerve 2009;39(6):787-799

24 Karabekmez FE, Duymaz A, Moran SL. Early clinical outcomes with the use of decellularized nerve allograft for repair of sensory defects within the hand. Hand (NY) 2009;4(3):245-249

25 Cho MS, Rinker BD, Weber RV, et al. Functional outcome following nerve repair in the upper extremity using processed nerve allograft. J Hand Surg Am 2012;37(11):2340-2349

26 Brooks DN, Weber RV, Chao JD, et al. Processed nerve allografts for peripheral nerve reconstruction: a multicenter study of utilization and outcomes in sensory, mixed, and motor nerve reconstructions. Microsurgery 2012;32(1):1-14

27 Kim DH, Kam AC, Chandika P, Tiel RL, Kline DG. Surgical management and outcome in patients with radial nerve lesions. J Neurosurg 2001;95(4):573-583

28 Ray WZ, Mackinnon SE. Clinical outcomes following median to radial nerve transfers. J Hand Surg Am 2011;36(2):201-208

29 Brown JM, Tung TH, Mackinnon SE. Median to radial nerve transfer to restore wrist and finger extension: technical nuances. Neurosurgery 2010;66(3, Suppl Operative):75-83, discussion 83

30 Lowe JB III, Sen SK, Mackinnon SE. Current approach to radial nerve paralysis. Plast Reconstr Surg 2002;110(4):1099-1113

31 Brown JM, Mackinnon SE. Nerve transfers in the forearm and hand. Hand Clin 2008;24(4):319-340, v

32 Boyd KU, Nimigan AS, Mackinnon SE. Nerve reconstruction in the hand and upper extremity. Clin Plast Surg 2011;38(4):643-660

33 Boutros S, Nath RK, Yüksel E, Weinfeld AB, Mackinnon SE. Transfer of flexor carpi ulnaris branch of the ulnar nerve to the pronator teres nerve: histomorphometric analysis. J Reconstr Microsurg 1999;15(2):119-122

34 Hsiao EC, Fox IK, Tung TH, Mackinnon SE. Motor nerve transfers to restore extrinsic median nerve function: case report. Hand (NY) 2009;4(1):92-97

35 Kapandji A. Biomechanics of pronation and supination of the forearm. Hand Clin 2001;17(1):111-122, vii

36 Zheng XY, Hou CL, Gu YD, Shi QL, Guan SB. Repair of brachial plexus lower trunk injury by transferring brachialis muscle branch of musculocutaneous nerve: anatomic feasibility and clinical trials. Chin Med J (Engl) 2008;121(2):99-104

37 Ray WZ, Yarbrough CK, Yee A, Mackinnon SE. Clinical outcomes following brachialis to anterior interosseous nerve transfers. J Neurosurg 2012;117(3):604-609

38 García-López A, Sebastian P, Martinez F, Perea D. Transfer of the nerve to the brachioradialis muscle to the anterior interosseous nerve for treatment for lower brachial plexus lesions: case report. J Hand Surg Am 2011;36(3):394-397

39 Wang Y, Zhu S. Transfer of a branch of the anterior interosseus nerve to the motor branch of the median nerve and ulnar nerve. Chin Med J (Engl) 1997;110(3):216-219

40 Vernadakis AJ, Humphreys DB, Mackinnon SE. Distal anterior interosseous nerve in the recurrent motor branch graft for reconstruction of a median nerve neuroma-in-continuity. J Reconstr Microsurg 2004;20(1):7-11

41 Mackinnon SE, Colbert SH. Nerve transfers in the hand and upper extremity surgery. Tech Hand Up Extrem Surg 2008;12(1): 20-33

42 Mannerfelt L. Studies on the hand in ulnar nerve paralysis. A clinical-experimental investigation in normal and anomalous innervation. Acta Orthop Scand 1966(Suppl 87):87, 1

43 Gaul JS Jr. Intrinsic motor recovery-a long-term study of ulnar nerve repair. J Hand Surg Am 1982;7(5):502-508

44 Haase SC, Chung KC. Anterior interosseous nerve transfer to the motor branch of the ulnar nerve for high ulnar nerve injuries. Ann Plast Surg 2002;49(3):285-290

45 Novak CB, Mackinnon SE. Distal anterior interosseous nerve transfer to the deep motor branch of the ulnar nerve for reconstruction of high ulnar nerve injuries. J Reconstr Microsurg 2002; 18(6):459-464

46 Battiston B, Lanzetta M. Reconstruction of high ulnar nerve lesions by distal double median to ulnar nerve transfer. J Hand Surg Am 1999;24(6):1185-1191

47 Farber SJ, Glaus SW, Moore AM, Hunter DA, Mackinnon SE, Johnson PJ. Supercharge nerve transfer to enhance motor recovery: a laboratory study. J Hand Surg Am 2013;38(3):466-477

48 Kale SS, Glaus SW, Yee A, et al. Reverse end-to-side nerve transfer: from animal model to clinical use. J Hand Surg Am 2011;36(10): 1631-1639.e2

49 Barbour J, Yee A, Kahn LC, Mackinnon SE. Supercharged end-toside anterior interosseous to ulnar motor nerve transfer for intrinsic musculature reinnervation. J Hand Surg Am 2012; 37(10):2150-2159

50 Tung TH, Barbour JR, Gontre G, Daliwal G, Mackinnon SE. Transfer of the extensor digiti minimi and extensor carpi ulnaris branches of the posterior interosseous nerve to restore intrinsic hand function: case report and anatomic study. J Hand Surg Am 2013;38(1):98-103

51 Phillips BZ, Franco MJ, Yee A, Tung TH, Mackinnon SE, Fox IK. Direct radial to ulnar nerve transfer to restore intrinsic muscle function in combined proximal median and ulnar nerve injury: case report and surgical technique. J Hand Surg Am 2014;39(7): 1358-1362 